\title{
O trotskismo e a Revolução Boliviana de 1952
}

Marcio Lauria Monteiro

Resumo: Baseado em pesquisa original e bibliografia especializada ainda pouco difundida, este artigo almeja trazer à tona a linha política e a atuação do Partido Obrero Revolucionario e da Quarta Internacional, ao longo da Revolução Boliviana de 1952. O autor destaca as ligações com os intensos debates e disputas à época travados no interior do movimento trotskista internacional, as quais se encontram no centro da sua divisão organizativa e diferenciação teórico-programática.

Palavras-chave: Trotskismo. Partido Obrero Revolucionario. Quarta Internacional. Revolução Boliviana.

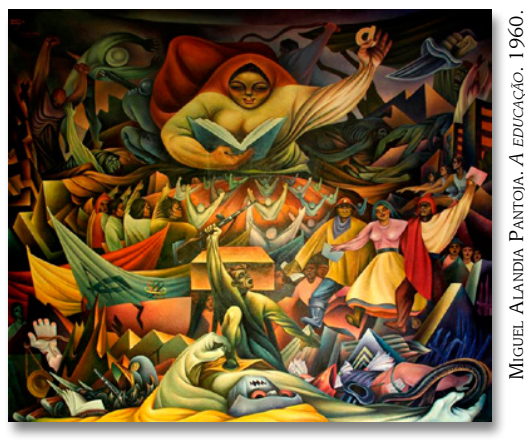

\section{Trotskyism and the 1952 Bolivian Revolution}

\section{Marcio Lauria Monteiro}

Mestre e doutorando em História Social pelo Programa de Pós-

Graduação em História da Universidade Federal Fluminense.

Pesquisador do Grupo de Pesquisa em História Contemporânea Apolônio de Carvalho (UFMS/CNPq) e ao Núcleo Interdisciplinar de Estudos e Pesquisas sobre Marx e o Marxismo (NIEP-Marx/UFF).

E-mail: marciolmonteiro@gmail.com.
Abstract: Based on original research and still little spread specialized bibliography, this paper aims to bring into light the political line and activity of the Partido Obrero Revolucionario and the Fourth International during the 1952 Bolivian Revolution. The author highlights its connections with the intense debates and disputes then having place inside the international Trotskyist movement, which are in the center of its organizational division and theoretical and programmatic differentiation.

Keywords: Trotskyism. Partido Obrero Revolucionario. Fourth International. Bolivian Revolution.

$$
\frac{\overline{\text { RECEBIDO 30.04.2017 }}}{\text { APROVADO 12.05.2017 }}
$$




\section{INTRODUÇÃO'}

Em abril de 2017, completaram 65 anos do começo da Revolução Boliviana de 1952. A história dessa revolução é a de um processo que fugiu largamente ao controle daqueles que o iniciaram, tendo sido a primeira da América Latina na qual o proletariado teve um papel determinante. Outro fator de destaque é que ela teve como um de seus importantes protagonistas uma organização trotskista, o Partido Obrero Revolucionario (POR), seção da Quarta Internacional (QI). O objetivo desse artigo, baseado tanto em pesquisa original quanto em uma bibliografia especializada ainda pouco difundida, é trazer à tona a linha política e a atuação do POR e da QI ao longo da revolução, destacando as ligações com os intensos debates e disputas à época travados no interior do movimento trotskista internacional, as quais se encontram no centro da sua crise - isto é, a sua crescente divisão organizativa e a diferenciação teórico-programática a partir do pós-guerra. A compressão desses elementos e de suas relações é de suma importância não só para uma história do trotskismo internacional e boliviano, mas para uma história do próprio processo revolucionário em questão.

\section{TROTSKISMO E SUA CRISE NO PÓS-GUERRA}

A Quarta Internacional (QI) surgiu de uma longa luta política, cujas raízes se encontram na Oposição de Esquerda do Partido Bolchevique, ala interna organizada em 1923, em torno da defesa de um retorno da democracia partidária e, especialmente, do poder direto das massas trabalhadoras - elementos que foram progressivamente suprimidos ao longo dos anos de guerra civil (1918 - 1921). Entre seus membros, se destacavam vários "velhos

\footnotetext{
1 Esse artigo é fruto de uma pesquisa parcialmente desenvolvida com recursos da Coordenação de Aperfeiçoamento de Pessoal de Nível Superior (Capes). Agradeço a Icaro Rossignoli e a Lucas Malaspina pelas conversas e pela ajuda na obtenção de parte do material bibliográfico utilizado.

2 Ainda não há uma "história geral" do movimento trotskista, predominando obras que tentam legitimar um entre os vários grupos em que ele se dividiu no pós-guerra ou pesquisas que se limitam a uma seção nacional. Para uma obra de caráter enciclopédico, ver Alexander (1991).
} 
bolcheviques", tendo Leon Trotski à frente. Derrotada nas instâncias partidárias em diferentes ocasiões ao longo de 1923 - 1928, seus membros foram expulsos do partido, exilados e perseguidos.

A partir da expulsão (1928), a Oposição de Esquerda se internacionalizou, tornando-se uma "fração pública" da Internacional Comunista (IC), na forma da Oposição de Esquerda Internacional. Já em 1933, diante da vitória nazista na Alemanha (sem resistência considerável do maior partido comunista fora da União Soviética) foi adotada a perspectiva de construir um novo partido internacional para lutar pelo socialismo revolucionário e a regeneração da democracia soviética. Fundada em 1938, a Quarta Internacional e as suas seções nacionais se apresentavam como as legítimas herdeiras da revolução soviética e lutavam ao redor do globo contra a socialdemocracia e o "stalinismo" (os comunistas da "degenerada" IC), pela hegemonia da classe trabalhadora.

Sua tarefa primordial seria conduzir as lutas da classe trabalhadora a uma revolução socialista, não apenas nos centros imperialistas, mas também nos países da periferia capitalista - que muitos adeptos do marxismo encaravam não estarem "maduros" para tal. Pois, de acordo com a Teoria da Revolução Permanente, desenvolvida por Trotski ante as experiências revolucionárias russas (de 1905 e de 1917) e, posteriormente, "generalizada" a partir da experiência revolucionária chinesa (1925 - 1927), na fase imperialista do desenvolvimento capitalista, a interligação orgânica entre burguesias periféricas, oligarquias rurais e capitais imperialistas não permitia nessa parte do globo uma "repetição" das revoluções de tipo "democrático-burguesas", como a vista na França em 1789. Portanto, a resolução das tarefas "nacional-democráticas" (reforma agrária, soberania nacional, república democrática) deveria se dar como parte de um único processo, protagonizado pelo proletariado e que "queimasse etapas", ao expropriar as classes possuidoras nativas e imperialistas, que contra ele se ergueriam. (TROTSKY, 2008; 2011).

Ainda que a QI tenha permanecido bastante marginal na maioria dos países em que obteve presença, houve alguns poucos lugares em que conseguiu se destacar - dentre os quais a Bolívia. Essa influência reduzida dos trotskistas se tornou ainda mais severa ao 
longo do pós-guerra. Primeiro, em decorrência do enorme baque que foi o assassinato de Trotski por um agente da polícia política de Stalin, em 1940, e a perda de vários outros dirigentes e quadros ao longo da guerra. Depois, pela crescente divisão pela qual essa organização internacional passou, após os esforços de reorganização do imediato pós-guerra.

Essa divisão não era apenas organizativa, mas também teórico-programática. Frequentemente reduzida ao chamado "pablismo"/"revisionismo pablista" - uma série de ideias novas que o então Secretário Geral da QI, "Michel Pablo" (Michalis Raptis), buscou impor à organização através de métodos burocráticos ao longo de 1951 - 1954 -, na realidade, ela envolveu releituras teórico-programáticas desenvolvidas por diferentes setores, ante um cenário de revoluções sociais bastante peculiares frente àquilo que se esperava a partir do cânone marxiano. Ocorridas na periferia capitalista, com protagonismo social de ex-camponeses recém -expropriados e de trabalhadores rurais e com protagonismo político de forças que não colocavam uma revolução socialista como tarefa historicamente imediata, essas revoluções foram o pivô da crise do trotskismo (MONTEIRO, 2016b).

\section{ABRIL DE 1952: DE UM PUTSCH A UMA INSURREIÇÃO POPULAR E PROLETÁRIA}

A Revolução Boliviana de 1952, apesar de algumas diferenças (em especial o protagonismo do proletariado urbano), é um importante episódio da história do trotskismo e é muito reveladora da sua crise. A história dessa revolução remonta a uma série de golpes de Estado.

Derrubado do poder em 1946, junto com o regime que então integrava, o Movimiento Nacionalista Revolucionario (MNR) ganhou por ampla margem as eleições presidenciais de 1951 (realizadas com base em sufrágio censitário). Esse resultado foi surpreendente, dado que o MNR havia conseguido apenas 1 dos 27 assentos parlamentares nas eleições de 1949. Seu candidato, Victor Paz Estenssoro, contou com o apoio do recém-formado Partido Comunista boliviano e, ao que tudo indica, também de alguns 
setores do $\mathrm{POR}^{3}$. Contudo, Estenssoro foi impedido de assumir a presidência pelas forças armadas, que instituíram uma junta militar com apoio do parlamento.

Em 9 abril de 1952, ante uma crescente insatisfação popular, o partido tentou chegar ao poder através de um putsch, em aliança com o general da Polícia Nacional, Hernán Síles (vice na chapa de Estenssoro). A trama deveria se limitar a um golpe militar-policial, mas rapidamente acabou se tornando uma insurreição popular. Em resposta à mobilização das tropas pró-governo, o MNR convocou setores do proletariado e da população a pegaram em armas. A partir daí, trabalhadores convocados por seus sindicatos marcharam sobre as principais cidades e nelas montaram barricadas (JOHN, 2009; ANDRADE, 2016).

O golpe projetado pela liderança do MNR não almejava mudanças sociais (ANDRADE, 2016). Surgido em 1941, no contexto de insatisfação social e nacionalismo decorrente da derrota da Bolívia para o Paraguai na Guerra do Chaco (1932-35), esse partido tinha como principal projeto político "modernizar" o país, através do fomento estatal à economia e contra a toda-poderosa oligarquia exportadora de estanho (la rosca) (ROCHA, 2006). Segundo a descrição do historiador Everaldo Andrade (2007), ele era composto por um "setor nacionalista da pequena-burguesia", orientado por uma "estratégia da revolução com conteúdo de reforma democrática e nacional" (ANDRADE, 2007, p. 18), um "grupo de profissionais liberais e burocratas identificado com o nacionalismo moderado [...] profundamente ligado por laços econômicos e políticos à elite política burguesa" (ANDRADE, 2007, p. 40).

Parte dos quadros fundadores do MNR, inclusive, já havia participado dos regimes militar-nacionalistas de David Toro (1936-37) e Germán Busch Becerra (1937-39). O partido integrou aquele de Gualberto Villarroel (que chegou ao poder através de um golpe em 1943 e foi removido por outro em 1946) (JOHN, 2009). Seu "nacionalismo" era tão amplo que abarcava até mesmo vertentes fascistas, que imprimiram a seu programa de 1942 traços claramente anti-semitas (ANDRADE, 2007).

3 Segundo John (2009), não há clareza da posição do partido, dada sua desorganização após uma onda repressiva, em 1949. Parece ter havido orientação de voto nulo por parte da direção, mas alguns setores teriam votado no MNR. 
Não obstante os objetivos do MNR, a tentativa de (re)conduzir Paz Estenssoro ao poder fugiu às suas mãos e foi transformada pela ação das massas populares e do proletariado em uma verdadeira revolução social, que derrotou e paralisou o grosso do aparato repressivo do Estado, através da formação de milícias proletárias e populares, culminando na formação da Central Obrera Boliviana (COB). Foram as massas insurretas que levaram o MNR ao poder, saudando Síles e, depois, Paz Estenssoro, quando este retornou do exílio na Argentina e assumiu a presidência (ANDRADE, 2007; 2016).

\section{DA DUALIDADE DE PODERES À NORMALIZAÇÃO BURGUESA}

A COB surgiu no dia 18 de abril como uma poderosa organização sindical (com participação também de estudantes e camponeses), inicialmente detendo o controle de significativa parte das milícias populares e configurando-se enquanto um verdadeiro segundo poder. No léxico comunista, se configurava uma situação de "dualidade de poderes", na qual "as classes hostis se apoiam cada uma em organizações governamentais essencialmente incompatíveis - uma caduca, outra em processo de formação que se repelem uma a outra em cada passo da esfera do governo" (TROTSKY, 2007, p. 203). Essa situação se mostra instável, dado que uma das classes buscará o monopólio do poder contra a outra. (TROTSKY, 2007).

Nesse sentido, não faltaram conflitos entre a COB e o governo nos primeiros momentos do processo revolucionário. As duas principais forças no interior dessa organização, erguida a partir dos vários sindicatos bolivianos sob a iniciativa da Federação Sindical dos Trabalhadores Mineiros da Bolívia (FSTMB), eram o POR e um setor do próprio MNR (que teve tensões com a ala dirigente e governamental do partido nos primeiros momentos) (ANDRADE, 2016).

Fundado em 1935 por exilados na Argentina, o POR possuía considerável e histórica inserção entre os trabalhadores das minas de estanho. Em 1946, quando do $4^{\circ}$ Congresso da FSTMB, foi ele 
que deu as bases para o manifesto programático então adotado, as chamadas Teses de Pulacayo (LORA, 1977), segundo as quais "o proletariado, mesmo na Bolívia, é a classe social revolucionária por excelência", dado que "não surgiu no cenário político uma burguesia capaz de liquidar o latifúndio e as outras formas econômicas pré-capitalistas; de realizar a unificação nacional e a libertação do domínio imperialista" (LORA, 1977, p. 245-252). As Teses apontavam, em clara sintonia com a Teoria da Revolução Permanente, que:

[...] o proletariado dos países atrasados está obrigado a combinar a luta pelas tarefas democrático-burguesas com a luta pelas reivindicações socialistas. Ambas etapas - a democrática e a socialista - "não estão separadas na luta por etapas históricas, ao invés, decorrem imediatamente umas das outras". (POR, [1946], [s.p.]).

O MNR, por sua vez, também possuía importante inserção entre os trabalhadores mineiros. Entre os importantes sindicalistas de suas fileiras, se destacava Juan Lechín, histórico líder mineiro, que foi o principal nome à frente das massas durante a insurreição de abril, tendo partido dele os chamados à ação proletária. Os postos de liderança na COB foram majoritariamente ocupados por esses membros do MNR, tendo Lechín sido escolhido seu Secretário Geral.

A tensão entre o novo governo e as massas insurretas não tardou a aparecer. De um lado, a liderança do MNR no governo, organizada ao redor de Paz Estenssoro, dava declarações à imprensa de que era absolutamente contra o "comunismo" e de que almejava a restauração da normalidade institucional, buscando, assim, uma aproximação com os EUA. De outro lado, fábricas eram ocupadas, camponeses tomavam as terras dos latifundiários e a COB demandava a nacionalização e a autogestão proletária de minas e ferrovias, assim como uma profunda reforma agrária. Diante dessa mobilização e do poder militar detido pela COB, que demandava representação no governo, o MNR acabou por conceder um "co-governo" a seus dirigentes. Assim, Lechín foi nomeado Ministro das Minas e Petróleo e German Butron, sindicalista 
do setor têxtil, Ministro do Trabalho, além de outros sindicalistas terem obtido cargos de segundo escalão. Na avaliação de diferentes historiadores e analistas (ANDRADE, 2007; 2016; JOHN, 2009; VILLA, [1992]), essa medida permitiu ao MNR cooptar lideranças proletárias e populares para o reestabelecimento da ordem burguesa, tendo esse "co-governo" sido um elemento-chave para reverter as mobilizações e desmantelar a situação de dualidade de poderes.

Paralelamente, o MNR também realizou concessões parciais às demandas das massas insurretas, em especial a nacionalização das minas, decretada em outubro, feita mediante compensação monetária aos proprietários e limitando a gestão sindical da produção, diferentemente do que exigiam os mineiros. A reforma agrária foi decretada em agosto de 1953, mas preservou o grande latifúndio, não atendeu às demandas de restituição de terras dos povos originários e redistribuiu apenas uma pequena porção de propriedades. Apesar dessas limitações, tais concessões reduziram sobremaneira as mobilizações que vinham pressionando o governo (ANDRADE, 2016; JOHN, 2009).

Com o passar dos anos, o MNR foi recuando nas suas reformas e se aproximando cada vez mais dos EUA, que chegaram a ter assessores ocupando postos importantes no governo e impuseram uma série de demandas político-econômicas em troca de empréstimos. A partir de 1953, oficiais militares passaram a receber treinamento de programas dos EUA no Canal do Panamá; em 1955, uma nova legislação para o setor do petróleo realizou concessões aos interesses norte-americanos; em 1956, foi finalizada a restruturação de uma força armada nacional sob controle governamental, em detrimento das milícias populares, da desestatização do setor petroleiro e da implementação de um plano econômico tutelado pelo FMI (ANDRADE, 2016; QUINTEIROS; MOREIRA; RAMIREZ, 2012). Também nesse ano, quando a insurreição já havia dado lugar à "normalidade", foram enfim convocadas as eleições para um governo constitucional - o primeiro pleito boliviano realizado com sufrágio universal - as quais haviam sido previstas ainda em julho de 1952. O candidato do MNR, Hernán Síles, foi eleito presidente com $84,4 \%$ dos votos, tendo o POR obtido meros $0,2 \%$ e 
não conseguido assentos no parlamento bicameral (HOFMEISTER; BAMBERGER, 1993).

Em 1964, esse rumo à direita foi aprofundado ainda mais, com a ascensão ao poder, via golpe militar, do general René Barrientos, apoiado por uma ala do próprio MNR, cuja gestão terminou de entregar as riquezas do país ao capital imperialista norte-americano e de reverter as conquistas da revolução, a partir de um conflito direto contra a classe trabalhadora organizada na $\mathrm{COB}$, em particular os mineiros. O proletariado boliviano só voltaria a mostrar novamente sua poderosa força em 1971, com a Comuna de La Paz. (ANDRADE, 2016). Ademais, durante seus anos no poder, o MNR ignorou ou mesmo suprimiu as demandas de autodeterminação/ autonomia dos povos originários, que compõem cerca de 80\% da população da Bolívia e que se tornaram a principal força contestatória nos anos 1980-1990 (ROCHA, 2006).

\section{A ATUAÇÃO E LINHA POLÍTICA DO POR E DA QUARTA INTERNACIONAL}

Graças à sua inserção entre os mineiros, o POR ocupou papel de destaque na fundação da COB e em sua liderança, ainda que esta estivesse majoritariamente nas mãos do grupo de Lechín - o que significava ter influência sobre aquilo que Guillermo Lora (1977), um dos dirigentes históricos do partido, afirmou ter se tornado "a força política mais importante no país" (LORA, 1977, p. 279), ao redor da qual passara a ser travada a disputa por seu controle.

Considerando que o trotskismo se reivindicava herdeiro político da revolução soviética e legítimo representante do socialismo revolucionário, em contraposição às políticas do "stalinismo" e da social-democracia - por ele acusadas de "colaboração de classes" - seria razoável assumir que a linha do POR foi de disputa pelo poder contra o MNR, se lançando como alternativa de liderança e lutando pela constituição de um regime proletário com base na COB (ou em algum outro órgão classista), para transformar a insurreição em revolução socialista. Afinal, foi essa a linha seguida pelo Partido Bolchevique em 1917 - ao menos após a batalha encabeçada por Lênin na Conferência de Abril, na qual defendeu a 
linha de "Nenhum apoio ao Governo Provisório. Explicar as falsidades de suas promessas [...]. Desmascarar esse governo, que é um governo de capitalistas [...]", e de "[...] explicar às massas que os Sovietes de deputados operários são a única forma possível de governo revolucionário", propagandeando "a necessidade que todo o poder do Estado passe aos Soviets de deputados operários" (LENIN, [1917], [s.p.]).

Todavia, houve um verdadeiro abismo entre essa linha bolchevique e a adotada pelo POR e pela QI. A despeito da sua influência entre um dos setores mais combativos e organizados do proletariado boliviano e na contramão da Teoria da Revolução Permanente e das Teses de Pulacayo, o POR conferiu "apoio críti$\mathrm{CO}^{\prime}$ ao governo e, especialmente, ao que chamava de "ala esquerda" do MNR - a ala sindicalista de Lechín -, visando pressioná-la para que rompesse com a "ala direita" - de Paz Estenssoro e Síles - e formasse um regime que supostamente seria a antessala da "ditadura do proletariado". Para favorecer um giro à esquerda do governo e dar os primeiros passos nesse plano, defendeu a entrada de representantes sindicais no ministério, com vistas a favorecer essa "ala esquerda" a encaminhar as demandas das massas. Essa é a conclusão da pesquisa do historiador trotskista Sándor John (2009), associado à League for the Fourth International), da pesquisa/polêmica do militante trotskista José Villa ([1992]), ex-militante do POR, e da obra do já mencionado historiador Everaldo Andrade (2007) acerca da Revolução Boliviana. ${ }^{4}$

Tal postura de disputa do governo e de apoio a uma parte dele, era baseada, conforme apontava a própria imprensa do POR (Lucha Obrera, 11 de novembro de 1952), na caracterização daquele enquanto "pequeno-burguês" e do MNR enquanto "um partido em transição, de uma política tradicional ou reformista para a nova política da transformação revolucionária do proletariado enquanto o líder de toda a sociedade oprimida". Assim, mesmo reconhecendo que o MNR não era um partido proletário nem socialista revolucionário, o POR defendia que ele passasse por uma "mudança de

4 Everaldo Andrade dedicou sua dissertação (mestrado) à atuação do POR na revolução de 1952, mas ainda não foi possível a este autor acessá-la. 
composição social", para que pudesse atingir um programa capaz de fazê-lo "desempenhar um papel decisivo no presente período" (apud VILLA, [1992], [s.p.]). Ou seja, depositava confiança na "ala esquerda" do MNR para cumprir o papel de sujeito político de uma revolução socialista (ou dos primeiros passos de uma).

Era baseada em tais caracterizações que a liderança do POR não via necessidade de uma oposição intransigente ao governo e que almejava transformá-lo em um "governo operário e camponês", pela via de mudanças na composição do gabinete ministerial e pela "disputa" da "ala esquerda" do MNR. Essa perspectiva foi sistematicamente reproduzida no periódico do POR ao longo de 1952 - 1954, conforme demonstra Villa ([1992]). Na edição de 25 de maio de 1952 de Lucha Obrera, é apresentada uma síntese muito clara, na qual se afirma que o partido:

trabalha para que as massas e a ala esquerda do partido governante rumem para sua conclusão lógica, isto é, evoluam em direção a um governo operário e camponês. [...] Pela pressão das circunstâncias políticas, um governo pequeno-burguês pode, possivelmente, ser suplantado e transformado em um estágio do governo operário e camponês. É a tendência mais provável de um momento instável [...]. Isso envolve a derrota política da direita e a participação ativa do proletariado e dos camponeses no Estado. (apud VILLA, [1992], [s.p.]).

"Governo operário e camponês" foi um termo originalmente utilizado na tradição da IC e da QI como equivalente "popular" do conceito de "ditadura do proletariado" (THESES, [1922a]; TROTSKY, 2008). No entanto, a liderança que ascendeu ao comando da QI no pós-guerra - em especial o mencionado Michel Pablo e "Ernest Germain" (Ernest Mandel) - o transformou em um conceito de regime de transição entre capitalismo e "ditadura do proletariado": assentado sob bases capitalistas (inclusive com possível presença de representantes da burguesia), mas com uma liderança que, ainda que não socialista revolucionária, se supunha poder ser pressionada pela ação das massas a ir além de seu programa e expropriar a burguesia, transformando o regime. Conforme a nova estratégia desenvolvida por Pablo e companhia, a tarefa 
dos trotskistas nessa situação seria a de conferir "apoio crítico" ao governo, visando levá-lo a realizar tal transição, a partir de uma pressão constante sobre o partido no poder - inclusive possivelmente adentrando nele ("entrismo").

Elaborada entre 1948 - 1951, para explicar em retrospecto a experiência revolucionária iugoslava (1944 - 1948) - que, até a ruptura Tito-Stalin, uma ala majoritária da liderança da QI não via como uma revolução anticapitalista - e também para explicar e delinear uma posição ante a Revolução Chinesa (1949 - 1952), foi esse programa de transição gradual à ditadura do proletariado que determinou a ação do setor majoritário do movimento trotskista no pós-guerra. Dada a magnitude dessa releitura estratégica ante os pressupostos da Teoria da Revolução Permanente, que negavam a possibilidade de qualquer regime intermediário entre capitalismo e "ditadura do proletariado", ela está intimamente ligada à profunda crise pela qual passou tal movimento (MONTEIRO, 2016b).

Portanto, a orientação do POR não era um "desvio" em relação àquela assumida à época pela liderança da QI: o partido estava seguindo à risca os documentos do recente Congresso Mundial daquela e as resoluções emitidas pelo seu órgão dirigente, o Secretariado Internacional (SI), ante a insurreição de abril de 1952.

No $3^{\circ}$ Congresso Mundial da QI, realizado em agosto 1951, foi aprovado, sem votos contrários, o documento América Latina: Problemas e Tarefas, no qual se caracterizava o MNR enquanto a expressão boliviana de um fenômeno que estaria surgindo por toda América Latina, de "movimentos pequeno-burgueses anti -imperialistas". Apontava-se como tarefa prática a "participação e atividade, livre de todo sectarismo, nos movimentos e organizações que expressam as aspirações das massas, ainda que de forma confusa e indireta" - o que poderia incluir o MNR, caso "canalizasse" tais "movimentos e organizações" (LATIN..., 1951, p. 209; 211).

O documento estabelecia como tática geral para o POR atuar "nos círculos e organizações da classe trabalhadora, particularmente aqueles dos mineiros" e "tentar influenciar a ala esquerda do MNR, que se baseia precisamente nesses círculos" (LATIN..., 1951, p. 211). E como norte estratégico que, caso uma mobilização das massas ocorresse sob a hegemonia do MNR, ele deveria 
intervir no processo "com o objetivo de forçar quanto mais for possível a tomada do poder pelo MNR, na base de um programa progressivo de frente única anti-imperialista" (LATIN..., 1951, p. 211). Já se o POR angariasse considerável influência, ele deveria "lançar a demanda de um Governo Operário e Camponês dos dois partidos" (LATIN..., 1951, p. 211).

A "frente única anti-imperialista" foi uma tática adotada pelo IV Congresso da Internacional Comunista (1922), para orientar a ação dos PCs da periferia diante movimentos nacionalistas burgueses. Conforme as Teses Sobre a Questão do Oriente, essa tática seria, na periferia capitalista e ante o nacionalismo burguês, o equivalente à "frente única proletária" utilizada nos países centrais ante a socialdemocracia (aliança tática para a ação junto à independência política das partes envolvidas). Nesse sentido, através dela se almejava "desmascarar os vacilos e incertezas dos vários grupos do nacionalismo burguês" e ajudar "no desenvolvimento da vontade revolucionária e no esclarecimento da consciência de classe dos trabalhadores, incitando-os a lutar não somente contra o imperialismo, mas contra todo tipo de opressão feudal" (THESES,1956, p. 390).

As Teses eram um tanto quanto ambíguas. Apesar de compararem a "frente única anti-imperialista" com a "frente única proletária", davam margem a entender que a revolução na periferia capitalista não teria caráter socialista, pois os comunistas deveriam conformar uma aliança com o nacionalismo burguês em torno de um programa nacional-democrático, para uma revolução de libertação nacional (mas mantendo sua independência política e defendendo os interesses do proletariado) (THESES, 1956). Essa possível interpretação das Teses é reforçada pela orientação, do mesmo ano, para os PCs indonésio e chinês tornarem-se frações das organizações nacionalista-burguesas Sarekat Islam e Kuomitang, às quais passaram a ser organizativamente subordinados (e, no caso do PC chinês, cada vez mais politicamente subordinado, no curso da revolução de 1925 - 1927).

Não há indícios de que Trotski se opôs às perspectivas das Teses no IV Congresso, mas, a partir da trágica experiência da Revolução Chinesa, que o levou a "generalizar" a validade da sua Teoria da Revolução Permanente para o conjunto da periferia capitalista, não 
há vestígios em seus escritos da tática da "frente única anti-imperialista". Ao invés, há críticas a blocos políticos com o nacionalismo burguês. O mesmo pode ser dito em relação aos documentos dos primeiros anos da QI, ainda que ela reivindicasse formalmente o legado dos quatro primeiros congressos da IC. Assim, a aparição de tal tática nas citadas resoluções do $3^{\circ}$ Congresso Mundial da QI deve ser visto como uma mudança de linha. Ademais, ao ser orientada visando não uma revolução democrático-burguesa (considerada irrealizável em separado da socialista pela Teoria da Revolução Permanente), mas sim a formação de um "governo operário e camponês" tido como antessala da "ditadura do proletariado", representava uma mudança também em relação às próprias Teses do Oriente.

A "frente anti-imperialista" não era uma novidade para o POR. Apesar de seus documentos basilares, adotados em 1938, não falarem dessa tática e, ainda, afirmarem que a "frente única proletária" seria a "única tática viável", anos mais tarde aquela começou a aparecer em suas resoluções e ações (LORA, 1978a). Em julho de 1949, em um contexto de repressão e perseguição, seu Comitê Central propôs uma "frente anti-imperialista" com o MNR e o Partido de Izquierda Revolucionaria (PIR), com base em um programa que mesclava demandas democráticas com outras anticapitalistas. A resolução já previa a dificuldade que seria os dois outros grupos aceitarem esse programa e declarava disposição em aceitar uma alternativa "reformista", ainda que tomando cuidado para "não perder sua própria fisionomia dentro da frente". A proposta, tornada pública em um manifesto no mês seguinte, era justificada pela posição "anti-imperialista" da "burguesia 'nacional'" (MNR) e pelo "giro à esquerda" do stalinismo (PIR) (JOHN, 2009, p. 104-105).

Já em 1952, seguindo as orientações do $3^{\circ}$ Congresso Mundial, uma circular aos comitês regionais do POR, preparada pelo dirigente Edwin Möller, em 14 de março, orientava a formação de uma "frente anti-imperialista", através de um já existente "Comitê de Coordenação Sindical" (o POR já possuía um histórico de colaboração com a ala do MNR de Lechín no movimento sindical) e de um já existente Comité Cuatripartido (envolvendo POR-MNR-PIR-PCB 
[recém-fundado PC Boliviano]). Nela, a orientação para o MNR não era a de "rachar ou dividir" o grupo, mas "penetrar seus círculos operários, armá-los teoricamente, e levá-los a evoluir à esquerda, juntos, em totalidade" (JOHN, 2009, p. 115-116). Todavia, segundo Lora (1978b), a proposta de transformar esses dois comitês em uma "frente anti-imperialista" teria sido "rechaçada" pelas demais organizações.

Mantendo as orientações, uma semana após o começo da revolução de 1952, o comitê regional de Cochabamba do POR emitiu um chamado ao MNR no qual, ao mesmo tempo em que defendia a formação de conselhos proletários e camponeses e o armamento dos trabalhadores, declarava que uma "frente anti-imperialista" havia sido realizada na prática e o convidava a formar um "bloco conjunto contra a feudo-burguesia imperialista", com base em um programa de demandas democráticas, abolição do trabalho compulsório no campo (pongaje) e aumento dos salários. Ademais, reforçava que não almejava "dividir o MNR" (JOHN, 2009, p. 130).

Da parte da direção da QI, a política anterior também foi mantida. Quando do começo da revolução, o SI publicou um curto artigo em sua revista, Quatrième Internationale (fevereiro-abril de 1952), no qual, baseado na perspectiva de que "A pressão das massas durante os próximos meses será refletida na ala esquerda do governo, que buscará destruir o poder econômico das classes proprietárias", apontou que o POR tinha o "dever de mobilizar as massas exploradas em torno de um programa revolucionário e de, além disso, ajudar a luta da ala esquerda do MNR contra a ala direita" (INSURRECTION..., 1952, p. 12). Nele, era reafirmada novamente a caracterização desse partido como "pequeno-burguês", a qual era estendida ao seu governo.

Em novembro de 1952, dando apoio à linha seguida pelo POR, a liderança internacional afirmou, em uma resolução do $12^{\circ}$ Pleno do seu Comitê Executivo Internacional (órgão do qual o SI era um braço operativo), que "A forma pela qual o POR tem atuado até o momento está correta no geral e corresponde à realidade objetiva, bem como às forças reais do partido" (BOLIVIA, 1952, p. 24). A resolução também legitimava a política de "apoio crítico" ao 
governo, "acompanhado por ação revolucionária direta entre as massas, com o objetivo de exercer e reforçar sua pressão e desenvolver suas organizações independentes nos sindicatos e nas milícias" (BOLIVIA, 1952, p. 24). ${ }^{5}$

Passado mais de um ano desde a insurreição, o SI publicou outro artigo em Quatrième Internationale (novembro de 1953), no qual continuava a endossar a linha perseguida pelo POR. E isso a despeito do governo de Paz Estenssoro àquela altura já ter girado consideravelmente à direita, negando implementar demandas vindas das massas e buscando uma firme aliança com a burguesia nativa e o imperialismo norte-americano - o que estava sendo feito com toda a cumplicidade da sua "ala esquerda", que, a despeito de suas diferenças, atuava como correia de transmissão das posições do governo entre as massas. Em tal artigo, afirma-se que, "diante dessas novas condições" caberia ao POR declarar "Nenhuma confiança no governo que capitula à reação e ao imperialismo!" e chamar a "ala esquerda" do MNR a "romper com a ala direita capitulacionista e tomar o caminho de um verdadeiro governo operário e camponês!" (BOLIVIE..., 1953, p. 84).

Conforme avaliam diferentes pesquisas, seguindo essa linha, o POR permitiu ser transformado em um instrumento da "ala esquerda" do MNR entre os setores mais radicais do proletariado boliviano, ao passo que tal ala e seus "ministros operários" foram transformados em um instrumento da "ala direita" do MNR e da burguesia boliviana, tendo essa verdadeira "correia de transmissão" garantido aos últimos fazerem apenas concessões parciais às massas insurretas e findarem a dualidade de poderes que havia se estabelecido em abril de 1952 (JOHN, 2009; VILLA, [1997]). Um exemplo pontual mas esclarecedor foi a participação de um dirigente do POR, Ernesto Ayala Mercado - junto a outros representantes das lutas rurais - na comissão formada pelo governo para

5 Contraditoriamente, em vários trechos a COB era caracterizada como "elemento proletário do poder dual", e o POR orientado a agitar por um regime de "comitês de trabalhadores, camponeses e da pequena-burguesia urbana e da Assembleia Nacional deles", um "governo da maioria política dos comitês e da sua Assembleia Nacional" (BOLIVIA, 1952, p. 25). Mas também reafirmava a perspectiva de formação de um "governo operário e camponês" com a "ala esquerda" do MNR (BOLIVIA, 1952, p. 26-27). 
elaborar uma reforma agrária, a qual cumpriu o papel de protelar a questão e apresentar às massas insurretas uma perspectiva de solução legal e pacífica, legitimada pela participação na comissão de setores combativos (ainda que, contraditoriamente, o POR tenha denunciado as manobras protelatórias do governo) (ANDRADE, 2007).

Apenas em fins de 1952, o POR realizou uma autocrítica da sua linha, reconhecendo que os ministros indicados pela COB acabaram atuando no sentido de submetê-la ao governo do MNR e de que a fração sindical do partido estava a capitular sistematicamente a Lechín e companhia. Isso levou a um chamado para que os ministros sindicalistas se demitissem, mas não foi acompanhado por um chamado para que a COB (ou algum outro órgão de poder proletário) assumisse o poder. Ademais, pouco depois, em janeiro de 1953, quando a "ala direita" do MNR tentou um golpe para deter exclusivamente o controle do governo, o POR respondeu com a demanda por um gabinete conjunto dele com a "ala esquerda" do MNR (VILLA, [1997]).

Já em março de 1953, seguindo as resoluções do $9^{\circ}$ Congresso do POR (dezembro de 1952), que apontavam como central a luta para que se formasse um gabinete com maioria de representantes da COB, o partido levantou a demanda de "Todo poder à COB!" - mas não na forma de um regime proletário e, sim, para que os sindicalistas ligados à "ala esquerda" do MNR assumissem o controle completo do gabinete ministerial. Pouco depois, em uma resolução do Birô Político do POR (23 de junho), essa linha foi explicitada pela demanda de "Controle total do Estado pela ala esquerda do MNR", embasada nas resoluções do $10^{\circ}$ Congresso do partido (junho de 1953), que enfatizaram uma perspectiva de promover a hegemonia da "ala esquerda" do MNR, possibilitando uma "coalização governamental entre o POR e o MNR, que seria uma forma de materializar a fórmula do 'governo operário e camponês', a qual, por sua vez, constituiria o estágio transitório rumo a uma ditadura do proletariado" (apud VILLA, [1997], [s.p.]). Seguindo a perspectiva de atribuir papel central à "ala esquerda" do MNR para uma revolução socialista, a liderança do POR reagiu a uma crise ministerial de agosto de 1953 argumentando que o 
slogan de "Todo o poder à esquerda do MNR!" seria adequado, pois "Um novo governo do MNR deste tipo implementaria as novas tarefas da revolução" (apud VILLA, [1997], [s.p.]).

Anos mais tarde, em 1963, o próprio Lora reconheceu, em uma autocrítica mais profunda feita em La revolución boliviana: Análisis crítico, que a orientação do POR "possuía os sinais de um enorme erro ideológico: o de acreditar que os trabalhadores poderiam chegar ao poder via Lechín", ao passo que "A palavra de ordem de 'Todo poder para a $\mathrm{COB}^{\prime}$ poderia ter levado os trabalhadores à vitória" (apud VILLA, [1997], [s.p.]). No entanto, segundo Villa ([1992], [s.p.]), além de não apresentar uma perspectiva de poder proletário através da COB ou outra organização classista, o POR não teria criticado aquela ter sido construída verticalmente, a partir das lideranças sindicais (algo muito distinto do tipo de poder dual que foram os soviets russos). Ao invés, o partido assumiu o comando real das atividades cotidianas da central, dado que as principais lideranças oficiais (da "ala esquerda" do MNR) foram cooptadas para cargos governamentais. Seus membros, especialmente Lechín, redigiam declarações públicas para aquelas e assumiram o jornal da COB (Rebelión), que não veiculava propostas de um governo alternativo ao do MNR, ao qual o jornal constantemente declarava apoio. A partir de tudo isso, Villa ([1997]) sintetiza da seguinte forma a dinâmica das forças políticas na Revolução Boliviana de 1952: "Enquanto Paz queria se alinhar atrás do imperialismo, Lechín se alinhou atrás de Paz e o POR atrás de Lechín" (VILLA, [1997], [s.p.]).

A atuação do POR ao longo do processo revolucionário não deixou de criar atritos internos - os quais cresceram ao ponto de uma divisão em três grupos. Alguns meses após seu $10^{\circ}$ Congresso, cujas resoluções principais foram escritas por Lora e que elegeu Hugo González Moscoso como Secretário Geral, se iniciou um conflito interno e com a liderança internacional. Em janeiro de 1954, o SI criticou tais resoluções (encarando-as como muito brandas para com o MNR) defendendo, ao invés, uma perspectiva de chamados para que a "ala esquerda" rompesse com a "direita" e assumisse uma orientação revolucionária, bem como de demandar por uma assembleia constituinte, de maneira a se aproximar das 
massas insatisfeitas com o governo. Dentro do POR, essa crítica foi apoiada por Moscoso, que vinha tendo conflitos com Lora e Möller, por estarem fazendo chamados públicos à formação de uma frente com a "esquerda" do MNR sem a concordância da direção do partido (JOHN, 2009). Moscoso recebeu apoio direto da direção internacional, através de Michel Pablo e do dirigente do Birô Latinoamericano da QI, "Juan Posadas" (Homero Frasnelli) (LORA, 1978c).

Segundo John (2009), a questão que separava os dois lados em conflito não era acerca do "apoio crítico" ao governo, ou se a "ala esquerda" do MNR era uma aliada em potencial para uma revolução socialista, mas sobre como buscar uma aliança com ela: se através da "pressão das massas" (Moscoso e Pablo/Posadas) ou se através de um bloco político conjunto (Lora/Möller). Conforme Lora (1978c), no pleno de março de 1954 do Comitê Central do partido, ele e Möller tentaram aprovar uma proposta de "frente de esquerda" com o MNR, a qual seria uma versão da "frente anti-imperialista" com um "programa trotskista". O pleno decidiu submeter a proposta ao $11^{\circ}$ Congresso do partido, previsto para fins daquele ano e, a partir de então, Lora e Möller organizaram a "Fração Operária Leninista" (FOL) e Moscoso, a "Fração Proletária Internacionalista" (FPI), para lutarem pela direção.

Durante o período pré-congressual, a FOL foi acusada de quebra de disciplina, por tentar levar a cabo sua política sem autorização da direção. Nos meses seguintes, sua política de "frente de esquerda" passou a se transformar, por iniciativa de Möller, em uma de "entrismo" no MNR, como forma de se aproximar das bases da sua "ala esquerda". A luta entre a FOL e a FPI assumiu contornos agudos pelo fato de o SI ter tomado o lado da segunda, acusando a primeira de se aliar aos setores que haviam rompido com a QI em fins de 1953, para formar a "fração pública" Comitê Internacional. Essa "fração pública" acusava Pablo e seus aliados de "revisionistas" ("pablistas"), por conta das propostas de redução do trotskismo a um grupo de pressão no interior dos PCs, supondo que o "stalinismo" realizaria um "giro revolucionário" sob pressão de uma "iminente" Terceira Guerra Mundial (MONTEIRO, 2016b). A FOL, porém, não possuía um alinhamento com os setores "anti -pablistas" (JOHN, 2009). 
O $11^{\circ}$ Congresso chegou a uma solução diplomática, formando uma direção paritária entre a FOL e a FPI. Apesar dos conflitos da FOL com o SI, Lora chegou a participar do $4^{\circ}$ Congresso Mundial da QI, em julho de 1954. Ao retornar ao país, em outubro, chegou ao final de uma conferência da FOL na qual, sob liderança de Möller, foi decido romper com a FPI e implementar o "entrismo" no MNR, além de uma posição de "neutralidade" ante o conflito Comitê Internacional vs SI. Ele e alguns outros membros da FOL permaneceram no POR, mas o partido estava dividido na prática, com cada fração funcionando de forma independente. Segundo John (2009), a separação entre Lora e Möller não foi acerca de fazer um "entrismo", mas da insistência do segundo de que os membros da liderança também participassem - levando, na prática, a uma entrada total no MNR.

Após algum tempo funcionando formalmente como um mesmo partido, a FPI e o restante da FOL se separaram oficialmente, em decorrência de uma garantia que a primeira teria conseguido da "ala esquerda" do MNR para, no pleito eleitoral previsto para 1956, ser reconhecida oficialmente como o POR. Em resposta, a FOL realizou sozinha um " $13^{\circ}$ Congresso", em outubro-novembro de 1955, e "expulsou" a FPI do partido, tendo surgido o POR-Masas, nome do periódico lançado pelo novo grupo de Lora (LORA, 1978c).

\section{CRÍTICAS E SUPOSTAS CRÍTICAS À LINHA GERAL DO POR}

À época da revolução, apenas setores muitos minoritários do trotskismo se contrapuseram à linha do POR aqui descrita. O falecido Lora e seus herdeiros políticos do POR-Masas se reivindicaram enquanto a ala do partido que não compactuava com ela, acusando a FPI de ser "pablista" e de ter bloqueado o desenvolvimento de uma linha socialista revolucionária (LORA, 1978c; CASTRO, 2015). Conforme visto, de fato houve um conflito interno, mas não acerca dos fundamentos de "apoio crítico" ao governo e de construir um "governo operário e camponês" com a "ala esquerda" do MNR, mas de como fazer isso. Inclusive, logo quando da eclosão da revolução, Lora sustentou a política de "apoio críti$\mathrm{CO}^{\prime \prime}$, em entrevista ao jornal da seção francesa da QI, chamado $L a$ Verité, em 17 de abril de 1952. 
Outra figura do trotskismo que se reivindicava crítico da linha seguida pelo POR era Nahuel Moreno, histórico dirigente argentino, que afirmou, em 1973, que a atuação do partido representou "uma das traições mais espetaculares do século 20" (MORENO, 2008, p. 24). Todavia, à época, a organização de Moreno apresentou apenas uma variante dessa linha: conforme a edição de 25 de maio de 1952 de seu jornal (Frente Proletario), o POR deveria exigir "que os ministros operários sejam eleitos e controlados pela Federação dos Mineiros e que os novos Centros Operários sejam integrados ao governo de Paz Estenssoro" (apud VILLA, [1997], [s.p.]). Em meados de 1953, tal organização passou a defender a linha de "Todo poder à COB!", mas o próprio Moreno declarou que ela era equivalente a "Todos os ministérios para a liderança da COB!" (JOHN, 2009).

Todavia, se Lora e Moreno, conhecidos como críticos "anti -pablistas" da linha do POR, não o foram de fato - ao menos à época da revolução -, dois outros setores do movimento trotskista, em grande parte ignorados até hoje, cumpriram tal papel.

Um deles foi a "Fração Leninista" (FL) do POR, ala minoritária do partido, crítica tanto do grupo de Lora-Möller quanto de Moscoso-Pablo/Posadas. Conforme a pesquisa de John (2009), a FL - completamente apagada da história do trotskismo boliviano era parte do comitê de Cochabamba do partido e tinha como líder um emigrado suíço, de pseudônimo "Juán Lopez", sendo muito ativa entre as lutas camponesas e indígenas da região, que é até hoje considerada o "celeiro" do país.

Essencialmente, a FL rejeitava de forma veemente a caracterização do governo do MNR como "pequeno-burguês" e a ideia de que seria possível transformar a natureza daquele através da "pressão das massas". Para ela, o MNR era "o partido da burguesia nacional" e seu governo uma "ditadura da burguesia". Assim, realizou duras críticas à linha da direção do POR, que considerava, segundo um antigo membro, o quéchua Modesto Sejas, uma "política ilusória e oportunista ante a 'esquerda' [do MNR], a qual espalhou ilusões entre as massas" (apud JOHN 2009, p. 156). Corresponsabilizando a direção do partido pelo atrelamento das massas ao governo e suas ilusões nele, que sistematicamente as traiu, essa fração acusou ainda a 
linha do $10^{\circ}$ Congresso de ter auxiliado o MNR a burocratizar os sindicatos e a frear ação das massas. Em relação aos "ministros operários", suas críticas apontavam que a política do POR havia "beirado a traição" e reafirmavam a passagem das Teses de Pulacayo caracterizando membros do movimento sindical que integrassem um governo burguês de "traidores" da classe. Opunha-se, portanto, à postura da direção do POR ante Lechín e companhia, a qual estaria espalhando "ilusões" nele, ao invés de "desmascará-lo" (apud JOHN, 2009, p. 155-156; 157).

A FL ainda criticava o que via como falta de democracia interna no POR e sua completa desorganização, acusando que as lideranças partidárias estariam sendo autoproclamadas pelos "figurões" locais, ao invés de eleitas, e que as informações da política da direção não estariam circulando devidamente. Se apresentando enquanto uma oposição a ambas FOL e FPI, ela tomava ainda o lado do Comitê Internacional contra o "pablismo" e chamava os demais membros do partido a estudarem as questões que causaram a saída daquele da QI. Demonstrava, assim, estar atenta às divergências travadas no seio do movimento trotskista internacional da época e suas ligações com os aspectos centrais da linha do POR. Todavia, segundo o relato de Sejas, sua delegação ao $11^{\circ}$ Congresso do partido teria sido detida pela polícia ao chegar em La Paz, tendo seu líder suíço e sua esposa sido deportados e outros membros forçados a fugirem do país ou a entrarem na clandestinidade, levando à desarticulação da fração e seu esquecimento na História.

O outro setor a contestar duramente a linha do POR e da direção internacional foi a tendência encabeçada por Sam Ryan e Dennis Vern no setorial de Los Angeles do Socialist Workers Party (SWP) dos EUA. Organizada desde pelo menos 1950, essa tendência interviu nos acalorados debates no interior do movimento trotskista internacional entre os defensores da nova estratégia de redução do trotskismo a um grupo de pressão sobre o "stalinismo" e o nacionalismo burguês ("pablistas") e aqueles que caracterizavam o "stalinismo" como intrinsecamente contrarrevolucionário, negando as transformações anticapitalistas que estava conduzindo em alguns lugares (os "trotskistas ortodoxos", que mais tarde formaram o Comitê Internacional). Ante a revolução boliviana, ela denunciou que, a despeito das suas diferenças, "pablistas" e 
"trotskistas ortodoxos" teriam sido cúmplices na adoção de uma linha que consideraram "traidora". ${ }^{6}$

Essa tendência reagiu logo no começo da revolução, com uma carta de junho de 1952 à direção do SWP, questionando se a mencionada entrevista de Lora ao La Verité correspondia à linha do POR. Contrapondo-se à caracterização do MNR como "pequeno -burguês", apontava que essa era a "base para uma atitude conciliatória" com o que considerava ser um partido e governo burgueses, comparando o apoio a esse e aos "ministros operários" com a linha dos bolcheviques pré-Conferência de Abril, de "apoio condicional" ao Governo Provisório de Kerenski. Criticava ainda como insuficiente o programa do POR, por não conter demandas anticapitalistas (RYAN, 1952). Segundo John (2009), apesar da direção do SWP nunca ter respondido, ela enviou a carta para o POR, dispondo-se a publicar uma possível resposta - que nunca foi realizada.

Em agosto de 1953, no documento Bolívia - O Colaboracionismo de Classe Ganha um Recruta, Ryan (1953) ligou a linha do POR à da liderança internacional do pós-guerra, que estaria a "descobrir" várias "situações excepcionais", nas quais as "tradições do leninismo" não se aplicavam, sendo substituídas pelos "conceitos e métodos do reformismo" (RYAN, 1953, p. 41). Assim, quando o POR caracterizava o governo do MNR como "pequeno-burguês", estaria seguindo a lógica das "exceções", utilizada por aquela frente ao Leste Europeu (que teria tido um "status intermediário" de classe até 1948) e ao suposto "governo operário e camponês" da China, encarando que "o caráter de classe do Estado foi modificado sem revolução proletária, por manipulações nos círculos de poder" (RYAN, 1953, p.50 - 51). Estaria, portanto, aplicando a nova linha de transição gradual a uma ditadura do proletariado, realizada por intermédio de um partido não-marxista, que os trotskistas deveriam "apoiar criticamente" e "pressionar" à esquerda.

Após a formação do Comitê Internacional, por iniciativa da liderança "anti-pablista" do SWP, Ryan (1954) aproveitou a aproximação do POR-Masas de Lora para escrever mais uma crítica, em junho de 1954, intitulada A Revolução Boliviana e a Luta Contra

6 Para mais detalhes sobre essa tendência, ver Monteiro (2016a, p. 282-307). 
o Revisionismo. Com base em citações de Lucha Obrera e resoluções congressuais do POR, afirmava que o partido "traiu" a revolução, por conta da sua linha de "colaboração de classes" ante o governo do MNR e por descartar a estratégia leninista da tomada do poder, apostando em uma via gradual, de transformação do caráter de classe do Estado via "pressão das massas". Conectando essa linha com o "revisionismo pablista", corresponsabilizou os autointitulados "trotskistas ortodoxos" por terem mantido silêncio durante longo tempo, especialmente em relação à linha adotada ante a Revolução Chinesa, que teria sido o precedente estratégico daquela do POR. Também destacava a responsabilidade de Lora, então se reivindicando "anti-pablista", na "traição" desse partido. Utilizou o caso boliviano para ilustrar um dos argumentos centrais da sua tendência, segundo o qual o "revisionismo pablista" não tinha por fator determinante a questão do "entrismo" no "stalinismo" ou no nacionalismo burguês (conforme encaravam os "trotskistas ortodoxos"), mas a revisão da compreensão marxista do Estado, e afirmou que:

A luta contra o revisionismo pablista não pode ser confinada a palavras de ordem de "Nenhuma capitulação ao Stalinismo" e "Pelo direito do Partido de existir". Pelos últimos dois anos o POR foi organizativamente independente, enquanto capitulava politicamente ao governo burguês. Por quê? Porque o revisionismo do POR é em uma questão mais fundamental: a natureza de classe do Estado. E o revisionismo pablista como um todo também se baseia fundamentalmente na rejeição da posição marxista sobre a natureza de classe do Estado (RYAN, 1954, p. 14).

\section{CONCLUSÃO}

Trazer à tona a atuação do POR na Revolução Boliviana, sua ligação com a linha então predominante na liderança internacional do movimento trotskista e os debates que ela gerou é imprescindível para uma compreensão mais apurada da profunda crise de tal movimento. Por mais que seja discutível se o POR teria capacidade de levar o proletariado boliviano a transformar aquele 
processo em uma revolução socialista, o fato é que tanto suas alas majoritárias quanto as alas majoritárias da Quarta Internacional não atuaram nesse sentido.

Sua orientação era atingir uma transição ao socialismo de forma gradual, através de uma aliança programática com a "esquerda do MNR", de forma a "pressioná-la", através da ação das massas, a romper com os representantes burgueses e formar, a partir de mudanças ministeriais, um "governo operário e camponês" que seria um regime transitório para a ditadura do proletariado. Dessa forma, o POR e a liderança da QI romperam com aspectos fundamentais da Teoria da Revolução Permanente e da estratégia original do movimento trotskista, por apostarem no protagonismo de um partido não socialista revolucionário para a realização de uma transição ao socialismo e conceberem tal transição como algo gradual e realizável desde o interior do Estado burguês. Essa concepção foi compartilhada à época da revolução até mesmo por setores que, anos depois, se apresentaram como "anti-pablistas", como aqueles ligados a Guillermo Lora e Nahuel Moreno. Em contrapartida, aqueles que efetivamente se contrapuseram a ela, a "Fração Leninista" do POR e a Tendência Vern-Ryan do SWP, foram relegados ao esquecimento, sendo que, no caso desta última, ainda se apontaram as contradições dos autoproclamados "anti-pablistas" /"trotskistas ortodoxos" do Comitê Internacional, por terem compactuado com essa atuação do POR à época.

Vê-se, portanto, que estudar de forma mais apurada as análises, propostas e atuação dos trotskistas ante a Revolução Boliviana de 1952 força repensar algumas narrativas consagradas sobre o movimento trotskista internacional e sua crise no pós-guerra, que vai muito além de um conflito entre "revisionistas" e "ortodoxos", ou "sensatos" e "sectários", como costuma ser apresentada de forma predominante. 


\section{REFERÊNCIAS}

ALEXANDER, R. J. International Trotskyism, 1929-1985: A Documented Analysis of the Movement. Durham: Duke University Press, 1991.

ANDRADE, E. de O. A Revolução Boliviana. São Paulo: Editora da Unesp, 2007.

A Revolução Boliviana. In: QUINTEIROS, M.; MOREIRA, L. (org.). As revoluções na América Latina contemporânea. Maringá: UEM/PPGHistória, 2016. p. 249 - 287.

BOLIVIA. International Information Bulletin. New York: [s.n.], 1952.

BOLIVIE: Tensions entre le gouvernement et les masses. Quatriè Internationale, Paris, v. 11, n. 8-10, p. 84, 1953.

CASTRO, A. El P.O.R. y la IV Internacional. La Paz: Ediciones Masas, 2015.

HOFMEISTER, W.; BAMBERGER, S. Bolivia. In: NOHLEN, D. (ed.). Enciclopedia Electoral Latinoamericana y del Caribe. San José de Costa Rica: IIDH, 1993. p. 69 - 92.

INSURRECTION en Bolivie. Quatrième Internationale, Paris, v. 10, n. 2-4, p. 12, 1952.

JOHN, S. Bolivia's Radical Tradition: Permanent Revolution in the Andes. Tucson: University of Arizona Press, 2009.

LATIN America: Problems and Tasks. Fourth International, New York, v. 12, n. 6, p. 207-219, 1951.

LENIN, V. Sobre as tarefas do proletariado na presente revolução, [online], [1917]. Disponível em: <http://tinyurl.com/k7x9wcf>. Acesso em: 13 mar. 2010.

LORA, G. A History of the Bolivian Labour Movement, 1848-1971. Cambridge: Cambridge University Press, 1977.

Historia del POR: contribución a la historia política de Bolivia. Tomo I. La Paz: Ediciones ISLA, 1978a.

Historia del POR: contribución a la historia política de Bolivia. Tomo II. La Paz: Ediciones ISLA, 1978b.

Historia del POR: contribución a la historia política de Bolivia. Tomo III. La Paz: Ediciones ISLA, 1978c. 
MONTEIRO, M. A. L. de M. O movimento trotskista internacional e as revoluções do pós-guerra: uma análise de suas (re)leituras teóricas e programáticas (1944-63). 2016. 423f. Dissertação (Mestrado em História Social) - Programa de Pós-Graduação em História, Universidade Federal Fluminense, Niterói, RJ, 2016a.

MONTEIRO, M. L. O movimento trotskista internacional e as revoluções do pós-guerra. Revista Outubro, Campinas, n. 27, p. 191-219, $2016 \mathrm{~b}$.

MORENO, N. O partido e a revolução. 2. ed. São Paulo: Sundermann, 2008.

POR - Partido Obrero Revolucionario, Sección Boliviana del CERCI. TESIS de Pulacayo: tesis central de la Federación Sindical de Trabajadores Mineros de Bolivia. Bolivia: [s.n.], [1946]. Disponível em: <http://tinyurl. com/gqnke3v>. Acesso em: 10 jul. 2015.

QUINTEIROS, M.; MOREIRA, L.; RAMIREZ, H. História da América pósindependente. Maringá: Eduem, 2012.

ROCHA, M. S. A Outra Volta do Bumerangue: Estado, Movimentos Sociais e Recursos Naturais na Bolívia, 1952-2006. In: ROCHA, M. S.; CÂMARA, M. A.; SEGABINAZZI, A. Bolívia: de 1952 ao Século XXI. Brasília: Funag/Ipri, 2006, p. $13-61$.

RYAN, S. A Letter on the Bolivian Revolution. Internal Bulletin, New York, V. 14, n. 1, p. 7-12, 1952.

Bolivia - Class-Collaboration Makes a Recruit. Internal Bulletin, New York, v. 15, n. 17, p. 41 - 51, 1953.

The Bolivian Revolution and the Fight Against Revisionism. Debate Bulletin, New York, ano 22, p. 01 - 20, 1954.

THESES on Comintern Tactics. In: Congress of the Communist International, 4., [1922a]. Petrograd; Moscow. Annales... Petrograd; Moscow: Communist International, [1922a]. Disponível em: <http://tinyurl.com/ju8rwzv>. Acesso em: 27 nov. 2015.

THESES on the Eastern question adopted by the fourth Comintern congress. In: DEGRAS, J. (ed.). The Communist International, 1919-1943. v. I. Londres: Oxford University Press, 1956, p. 382-392.

TROTSKY, L. A teoria da revolução permanente. São Paulo: Sundermann, 2011. [Compilação]. 
História da Revolução Russa. Tomo I. Parte I. São Paulo: Sundermann, 2007 [1930].

O programa de transição para a revolução socialista. São Paulo: Sundermann, 2008 [1938].

VILLA, J. A Revolution Betrayed: The POR and the Fourth International in the Bolivian Revolution. [S.l.: s.n.], [1992]. Disponível em: <http://tinyurl. com/zkhg4wq>. Acesso em: 3 nov. 2014. 